\title{
Novel Bayesian Additive Regression Tree methodology for flood susceptibility modeling
}

\section{Saeid Janizadeh}

Tarbiat modares university

Mehdi Vafakhah ( $\nabla$ vafakhah@modares.ac.ir)

Tarbiat Modares University https://orcid.org/0000-0002-8113-9113

\section{Zoran Kapelan}

Delft university

Naghmeh Mobarghaee Dinan

Shahid Beheshti University

\section{Research Article}

Keywords: Flood susceptibility mapping, Bayesian, Regression Tree, Ensemble model, Bayesian Additive Regression Tree (BART)

Posted Date: July 9th, 2021

DOl: https://doi.org/10.21203/rs.3.rs-267890/v1

License: (c) (1) This work is licensed under a Creative Commons Attribution 4.0 International License. Read Full License 


\section{Abstract}

Identifying areas prone to flooding is a key step in flood hazard management. The purpose of this study is to develop and present a novel flood susceptibility model based on Bayesian Additive Regression Tree (BART) methodology. The predictive performance of new model is assessed via comparison with the Naïve Bayes (NB) and Random Forest (RF) based methods that were previously published in the literature. All models were tested on a real case study based in the Kan watershed in Iran. The following fifteen climatic and geo-environmental variables were used as inputs into all flood susceptibility models: altitude, aspect, slope, plan curvature, profile curvature, drainage density, distance from river distance from road, stream power index (SPI), topographic wetness index (TPI), topographic position index (TPI), curve number (CN), land use, lithology and rainfall. Based on the existing flood field survey and other information available for the analyzed area, a total of 118 flood locations were identified as potentially prone to flooding. The data available were divided into two groups with $70 \%$ used for training and $30 \%$ for validation of all models. The receiver operating characteristic (ROC) curve parameters were used to evaluate the predictive accuracy of the new and existing models. Based on the area under curve (AUC) the new BART (86\%) model outperformed the NB (80\%) and RF (85\%) models. Regarding the importance of input variables, the results obtained showed that the altitude and distance from the river are the most important variables for assessing flooding susceptibility.

\section{Introduction}

Any unforeseen natural occurrence and, in the event of an emergency that weakens or destroys economic, social and physical capacity, such as loss of life and finances, destruction of infrastructure, economic resources and areas of employment, is defined as a natural disaster, highlights include earthquakes, floods, drought, seawater, volcanoes, landslides, hurricanes and natural pests (Vetrivel et al. 2018). Flooding as one of the major natural disasters that have occurred is very important in terms of economic losses and serious humanitarian concerns, in other words, the flood phenomenon is one of the most dynamic and disruptive natural events that put human life and property and social and economic conditions at greater risk than any other natural disaster (Rahmati et al. 2016; Yariyan et al. 2020). Flooding is an influx of water that overwhelms the surrounding and marginal areas and may cause damage to agricultural land, urban areas and tolls (Perera et al. 2015). Flooding is one of the most important hydro-ecological phenomena of nature that causes damage to human achievements at all times (Woodward et al. 2014; Darabi et al. 2019; Vafakhah et al. 2020). Among the populated areas and centers, there is the highest risk and potential for tangible physical damage caused by the flood. In recent years, the increase in urban flood hazards, particularly along the river banks, has resulted in the risk of flooding for residents and movable property in the area (Choubin et al. 2019). Due to the varying climate, unpredictable temperatures and rainfall in many of Iran's watersheds, several floods occur every year (Tehrany et al. 2014). Limiting environmental resources, reducing and destroying them as a result of the expansion of human activities, poses many challenges for today's society and the next generation. The Kan watersheds have not been impacted by these natural disasters and have been affected by flooding 
annually; studies show that the Kan watershed is vulnerable to floods. The emergence of restaurants, leisure, tourist and pilgrimage centers adjacent to the steep rivers Kan watershed have increased the potential for damage. Seven important flood events were recorded in this watershed, causing damage to industrial, residential, agricultural land use, and fatalities, according to the available information.

Reducing human casualties as well as damage to property and the environment is a key objective shared by countries most often impacted by natural disasters and they are increasingly conducting feasibility studies with economic analysis to mitigate the effects of these disasters (Molinos-Senante et al. 2011). Although floods cannot be prevented, the analysis of damage can be mitigated through appropriate analysis and forecasting techniques (Heidari 2014). The first step is to identify flood-prone areas with potential for flooding and prepare flood maps (Janizadeh et al. 2019; Hosseini et al. 2020). One way to prevent and reduce flood damage is to provide people with reliable information through flood hazard zoning maps (Cook and Merwade 2009). Mapping the hazard of floods is an essential step to predict the likelihood of a flood and to reduce and control potential floods. To this end, the modelling of flood hazards, which may involve multi-temporal data sets, is required. Recently, with the advancement in computer science, machine learning methods have been successfully applied in assessing flood hazards with higher accuracy. However, there is no agreement which method or set of methods can provide the best prediction.

The prediction and determination of flood susceptibility areas have been investigated by various researchers. Rapid access to satellite imagery based on remote sensing data has increased the use of geographic information systems in the preparation of flood susceptibility maps. A wide range of modelling techniques has been proposed and used in natural disaster assessment including Al based techniques (Sayers et al 2014). In recent years, Bayesian methods, partly because they are over-resistant to the presence of small sample sizes and can control missing or incomplete data, have been developed to assess and model flood sensitivity such as Naïve Bayes (Liu et al. 2016; Pham et al. 2020b; Tang et al. 2020). Also use of regression tree machine learning models such as Random Forest (RF) (Arabameri et al. 2020; Chen et al. 2020; Vafakhah et al. 2020), Decision Tree (Khosravi et al. 2018; Costache 2019; Janizadeh et al. 2019; Pham et al. 2020a), Logistic Regression (Shafapour Tehrany et al. 2017; Al-Juaidi et al. 2018; Tehrany and Kumar 2018) due to the appropriate capability of these models in modeling nonlinear phenomena such as flood, has been considered by researchers in this field.

Machine learning algorithms by default usually present point estimates only, and so decisions are made ignoring the uncertainty surrounding these estimates. In recent years, the use of ensemble models has attracted the attention of researchers in various fields, ensemble models because they benefit from several individual models and therefore have better performance than individual models (Al-Abadi 2018; Tehrany et al. 2019a; Costache and Bui 2020; Shahabi et al. 2020). Bayesian Additive Regression Tree is one of the new ensemble models that combined from Bayesian and Regression tree algorithms and due to this model benefit Bayesian framework can give access to the full posterior distribution of all unknown parameters in the model, which can be useful in decision-making and reduce uncertainty. Due to the fact that the flood is a non-linear phenomenon and has a lot of the uncertainty, use of appropriate models that 
have the ability to predict this phenomena and reduce uncertainty is essential in the management, planning and prevention of the hazard of these phenomena.

Therefore, the purpose of this study is to develop and present a new flood susceptibility model based on the ensemble type Bayesian Additive Regression Tree (BART) method. The new method will be compared with the Naïve Bayes (Bayesian type) and Random Forest (regression tree type) based models to evaluate the predictive performance of the new method.

\section{Data For Flood Susceptibility Modelling 2.1 Description of the study area}

The Kan River watershed is $200 \mathrm{~km}^{2}$ and is located northwest of Tehran, Iran. This watershed is located between latitudes $51^{\circ} 10^{\prime}$ and $51^{\circ} 23^{\prime}$ east and $35^{\circ} 46^{\prime}$ and $35^{\circ} 58^{\prime}$ north (Fig. 1). The average height of the watershed is 2428 meters, the average slope of the whole watershed is $43.4 \%$ and the most important river in this mountainous region is the Kan River. The study area is located in the southern margin of the central Alborz region in terms of geological status and has a mountainous climate and cold to moderate, the average annual rainfall is $414.13 \mathrm{~mm}$. The average annual discharge of the Kan River is $2.2 \mathrm{~m}^{3} / \mathrm{s}$ and its annual water volume is about 70 million $\mathrm{m}^{3}$. According to the available information, seven important flood events have been reported in the Kan watershed, which have caused damage to commercial and residential facilities, agricultural land uses and caused casualties in the region (Delkash et al. 2014).

\subsection{Flood Inventory Data Preparation}

In order to prepare a flood susceptibility map and flood probability, it is necessary to analyses historical and recorded floods. The Kan watershed has been severely affected by dangerous floods in recent decades, causing extensive damage and casualties. According to historical floods recorded in the study area by Regional Water Company of Tehran Providence (1954/8/27, 1955/6/9, 1978/3/7, 1981/7/25, $1986 / 2 / 2,1995 / 4 / 23,1996 / 4 / 3$ ) as well as field visits and interviews with local indigenous individuals in 2019/10/5 to 2019/10/9 and identification of flood-affected areas by GPS equipment (Fig. 2), 118 flood locations were identified in the area. A total of 118 non-flood points were randomly placed in the interfluvial area, or within very steep altitude where the flood phenomenon is almost impossible assigned to the study area. The position of the flood and non-flood locations are presented in Fig. 1. After preparing flooding and non-flooding locations, the data were divided into two categories of training and validation for modeling, so that $70 \%$ of the data were used for training and $30 \%$ for validation (Ahmadlou et al. 2019; Choubin et al. 2019). The flowchart of research methodology are given in Fig. 3.

\subsection{Spatial Data Preparation}

Floods are one of the natural phenomena and are affected by various climatic and geo-environmental factors. In this study, the following fifteen climatic and geo-environmental variables are used as potential 
explanatory factors for flood susceptibility at a given location: altitude, aspect, slope, plan curvature, profile curvature, drainage density, distance form river distance from road, stream power index (SPI), topographic wetness index (TPI), topographic position index (TPI), curve number (CN), land use, lithology and annual rainfall.

The above 15 factors (i.e. potential flood susceptibility model independent variables) were confirmed as significant by using the multi-collinearity analysis. The multi-collinearity analysis evaluates the intensity of multiple correlations between considered variables by calculating the variance inflation factors (VIFs). The higher the value of the VIF the more likely it is that that variable does not play a significant role in flood susceptibility prediction (Miles 2014). In this study, the threshold of 5 was used for VIF to identify significant enough variables (Tehrany et al. 2019a; Hosseini et al. 2020). These values were estimated using the USDM package in $\mathrm{R}$ software. The analysis has shown that all fifteen variables shown here have VIF values below the above threshold (see Sect. 4.1) hence they have all been used a potential explanatory factors for assessing the flood susceptibility.

The values of above 15 variables were prepared based on previous studies (Figs. 4, 5 and 6 ). For this purpose, the digital elevation model (DEM) of the study area with resolution of $12.5 \times 12.5 \mathrm{~m}$ was used type L-band Synthetic Aperture Radar (PALSAR) (https://vertex.daac.asf.alaska.edu/\#). The aspect map was prepared based on DEM at nine class in the ArcGIS 10.5 software (Choubin et al. 2019; Janizadeh et al. 2019). Due to the slope effect on the surface runoff, the ground slope is one of the important factors in the occurrence of floods in watersheds (Tehrany et al. 2015; Chapi et al. 2017). The slope map was prepared based on the DEM in ArcGIS 10.5 software (Khosravi et al. 2018).

The plan and profile curvature are the spatial parameters used in the preparation of flood maps of watersheds. These variables were prepared in ArcGIS 10.5 software using a DEM with a resolution of $12.5 \mathrm{~m}$ (Rahmati et al. 2016; Hong et al. 2018). Drainage density of the study area in ArcGIS 10.5 environment was based on line density extension (Mahmoud and Gan 2018; Zhao et al. 2019). Distance from rivers is one of the most important factors affecting flooding of lands along rivers (Tehrany et al. 2014; Khosravi et al. 2016, 2018). This map was prepared using the Euclidean order in ArcGIS 10.5 software (Khosravi et al. 2018). Distance from road is one of the human factors affecting floods. This variable was prepared from 1: 50000 road map of Tehran province, ArcGIS10.5 software and Euclidean extension were used to determine the distance from road (Shafapour Tehrany et al. 2017).

The stream power index (SPI) is one of the indicators of important parameters in flood watersheds and the following relationship is defined (Tehrany et al. 2014; Shafizadeh-Moghadam et al. <2018):

$$
S P I=\text { CatchmentArea } * \tan (\text { slope })
$$

1

SAGA GIS 2.6 software was used to prepare this variable (Tehrany et al. 2014). 
Topographic position index (TPI) indicates the topographic status of the area, so that the positive values of this index indicate high altitudes and the negative values indicate low altitudes such as valleys (Papaioannou et al. 2015). Due to the role of topographic shape in the formation and formation of floods, this index is considered as one of factors affecting floods and this variable was prepared in SAGAGIS 2.6 software. TWI measures the effect of local topography on runoff production and shows the long-term moisture content of a landscape (Hong et al. 2018; Khosravi et al. 2019), so this indicator is one of the influential variables in flood assessment in watersheds. This variable was obtained based on the following equation (Khosravi et al.2019) in SAGAGIS 2.6 software:

$$
T W I=\ln (\text { CatchmentArea } / \tan (\text { slope }))
$$

2

Lithology is one of the important factors in the flood phenomenon in watersheds due to its direct effect on the level of permeability and surface runoff (Rahmati et al. 2016). The geological map of the Kan watershed was prepared based on the geological map of 1: 100000 of the Iranian National Cartographic Center (NCC) and then turned into a raster layer with a resolution of 12.5. The lithology map of the study area was divided into 7 different classes. The soil type map was also prepared from the Administration of Natural Resources of Tehran Province and the vector file of this map was created with a raster format with pixel size of 12.5 meters using the ArcGIS 10.5 software (Tehrany et al. 2014).

Land use is the result of the interrelationships of socio-cultural parameters and the potential of the land (Rahmati et al. 2016; Bui et al. 2018) Changes in land use and land cover have significant results in flooding of watersheds (Khosravi et al. 2018). This map was prepared using images of Landsat 8 satellite imagery OLI sensors in 2019 and using the maximum likelihood algorithm and supervised classification in the ENVI 5.1 software and divided into four classes: orchard, rangeland, residential and rocky lands.

In order to prepare the annual rainfall map, the rainfall data of 7 gauge stations (inside and outside the watershed) were used in the period 1994-2019. After carefully examining the various interpolation methods in the ArcGIS 10.5 software, the distribution of annual rainfall in Kan watershed was prepared based on the ordinary Kriging method (due to the least error).

One of the most important factors in the occurrence of floods is soil conditions and different land uses, which directly affect the amount of water infiltration into the land. In other words, the curve number (CN) at the level of each area indicates the hydrological behavior of that area and its discharge regime during rainfall. In order to determine the $\mathrm{CN}$ map of the land use map and the hydrological soil groups map in ArcGIS software environment, it has been combined. Then, based on the tables related to the $\mathrm{CN}$ for different land uses of watersheds and according to hydrological soil groups map, the amount of CN was determined in the case of previous average humidity (Mahmoud and Gan 2018; Tang et al. 2018).

\section{Flood Susceptibility Models}




\subsection{Overview}

This section describes three different models for predicting flood susceptibility: BART, NB and RF. All models are based on different machine learning methods that predict the flood susceptibility defined as the probability of flood occurrence at a given location in the analyzed watershed. All three models have the same set of input variables, the fifteen explanatory variables described in Sect. 2.3. These model inputs were determined in all cases using correlation and multi-collinearity analysis (see next section). Finally, all models are trained and tested using the data described in the same section.

\subsection{Naïve Bayes Model}

The Bayesian method is a way of classifying phenomena based on the probability of the phenomenon occurring or not occurring. Based on the inherent characteristics of probability (especially probability division), Naive Bayes offer good results after receiving the initial practice (Rish and others 2001). Learning method in the simplest way, the base is the type of learning with the supervisor. Bayes suggests a way to calculate the posterior probability, $\mathrm{P}(\mathrm{c} \mid \mathrm{x})$, from $\mathrm{P}(\mathrm{c}), \mathrm{P}(\mathrm{x})$ and $\mathrm{P}(\mathrm{x} \mid \mathrm{c})$. The Naive Bayes classifier assumes that the effect of the predictor cost (x) on a given category (c) of the different predictor values is neutral. This assumption is known as conditional independence.

$$
P(c \mid x)=\frac{P(c \mid x) * P(c)}{P(x)}
$$

3

$$
P(c \mid X)=P\left(x_{1} \mid c\right) * P\left(x_{2} \mid c\right) * \cdots * P\left(x_{n} \mid c\right)
$$

4

where $P(c \mid x)$ is posterior probability of target, $P(c)$ is prior probability of class and $P(x)$ is the

prior probability of predictor (Zhang 2004). The e1071 package in R software was use for Naïve Bayes modeling.

\subsection{Random Forest Model}

Random Forest (RF) method among tree methods, it is a relatively complex method in which several decision trees are taught in order to increase the accuracy of the model. The result is a prediction of a group of decision trees. In the random forest learning method, each decision tree is taught using a random sample selected from the training data set. The total selection of predictive variables used to divide nodes is also random. In the random forest method, the two properties mtry and ntree are determined for the number of auxiliary variables used in each subset and the number of trees used in the forest, respectively. One of the advantages of a random forest is that it can be used for both classification and regression issues, which make up the majority of current machine learning systems. Random forest 
has parameters similar to the decision tree or "Bagging Classifier". Random forest adds randomness to the model as trees grow. Instead of searching for the most important features when dividing a "node", this algorithm looks for the best features among a random set of features. This leads to more variety and ultimately a better model. Therefore, in a random forest, only one subset of features is considered by the algorithm to divide a node. By adding a random threshold for each attribute, instead of searching for the best possible threshold, trees can be made even more random (Liaw et al. 2002). The randomForest package in R software was use for RF modeling.

\subsection{Bayesian Additive Regression Tree (BART) Model}

BART is a Bayesian approach to non-parametric output estimation using regression trees. The regression trees are relying on the return of the binary division of the predictive space into a set of superconductors to approximate certain unknown functions. The predictive space has dimensions corresponding to the number of variables. Tree-based regression models are capable of generating plenty of interaction and nonlinearity (Hill et al. 2020). Models consisting of a number of regression trees are much more capable of capturing interaction and nonlinearity than single trees, as are additives in $\mathrm{f}$.

BART can be considered a general collection of trees with a new estimation method based on a complete Bayesian probability model. The BART model in particular classification can be expressed in the following terms:

$$
P(Y=1 \mid X)=\phi\left(\tau_{1}^{N}(X)+\tau_{2}^{N}(X)+\cdots+\tau_{n}^{N}(X)\right.
$$

5

where $\varphi$ denotes the cumulative density attribute of the prevalent regular distribution. In this formulation, the sum-of-trees model serves as an estimate of the conditional probit at $x$ which can be besides issues modified into a conditional threat estimate of $Y=1$ (Kapelner and Bleich2013). The bartMachine package in R software was use for BART modeling.

\subsection{Model Validation and Performance Assessment}

The ROC curve characterizes the relative performance of each model. The ROC curve is a graph in which the ratio of pixels that occur or occurrences with the model is correctly predicted on the horizontal axis (True positive or specificity) against its complementary value versus the ratio of pixels that are incorrectly predicted (False positive or sensitivity) is drawn on the vertical axis (Frattini et al. 2010). Sensitivity a proportion of occurrence pixels that have been correctly predicted, so the larger this value, the more accurate the model is in determining the occurrence points. Also, the feature means a ratio of nonoccurring pixels that the model correctly predicted. The area below is called the AUC curve, which measures one aspect of performance. The value of AUC varies from 0 to 1, which is 0.5 times the random prediction and 1 is the excellent prediction (Yesilnacar and Topal 2005). In this study, the equations which have been used to calculate TPR, TNR, specificity, sensitivity and AUC are given bellow. 


$$
T P R=\frac{T P}{(T P+F N)}
$$

6

$$
T N R=\frac{T N}{(T N+F P)}
$$

7

$$
\text { Sensitivity }=\frac{\text { Numberofpositives }}{(\text { Numberofpositives }+ \text { Numberoffalsepositives })}
$$

8

$$
\text { Specificity }=\frac{\text { Numberoftruenegatives }}{(\text { Numberoftruenegatives }+ \text { Numberoffalsenegatives })}
$$

9

$$
A U C=\frac{\sum T P+\sum T N}{(P+N)}
$$

10

where, TP (true positive) and TN (true negative) are accurately classified pixel numbers, while FP (false positive) and FN (false negative) are falsely classified pixel numbers. $\mathrm{P}$ is the total number of floods and $\mathrm{N}$ is the total number of non-floods (Choubin et al. 2019; Khosravi et al. 2019).

\section{Results}

\subsection{Analysis of Independent Variables}

In order to build a flood susceptibility model, potential independent (i.e. input) variables are first analyzed for independence (via correlation) and linearity (via multi-collinearity analysis).

The results of the correlation study of the variables used in flood susceptibility modelling based on Spearman correlation test are shown in Fig. 7. As it can be seen from this figure, the analyzed variables have a relatively low correlation with each other hence they were all selected for further analysis.

In order to determine the appropriate inputs for flood susceptibility modelling, multiple multiplexing and tolerance tests were used in the R software environment using usdm package. In order to investigate the linearity of the VIF range, all variables with VIF value smaller than 5 were considered. The results of multicolinearity and tolerance surveys are shown in Table 1. The study of the linearity of the variables shows 
that all independent variables have VIF value smaller than 5 with highest linearity obtained for distance from the river with VIF of 2.39 and tolerance of 0.42 and least linearity obtained for the aspect variable with VIF of 1.07 and tolerance of 0.93 .

Based on above, all variables shown in Table 1 are selected as potential inputs into the flood susceptibility model.

Table 1

Multi-collinearity analysis base on VIF and

Tolerance to determine the linearity of the independent variables

\begin{tabular}{|lll|}
\hline Variables & VIF & Tolerance \\
\hline Altitude & 2.09 & 0.48 \\
\hline Aspect & 1.07 & 0.93 \\
\hline Slope & 1.57 & 0.64 \\
\hline Plan curvature & 1.9 & 0.53 \\
\hline Profile Curvature & 1.47 & 0.68 \\
\hline Drainage density & 2.33 & 0.43 \\
\hline Distance from River & 2.39 & 0.42 \\
\hline Distance from road & 2.09 & 0.48 \\
\hline SPI & 1.09 & 0.92 \\
\hline TPI & 1.37 & 0.73 \\
\hline TWI & 2.01 & 0.50 \\
\hline CN & 1.35 & 0.74 \\
\hline Land use & 1.29 & 0.77 \\
\hline Lithology & 1.27 & 0.79 \\
\hline Rainfall & 1.46 & 0.68 \\
\hline
\end{tabular}

\subsection{Tune parameters}

The result of tune parameters in BART model to flood susceptibility showed in Table 1 and Fig. 8. 
Table 2

Tune parameters in BART model

\begin{tabular}{|ll|}
\hline Parameters & Tune value \\
\hline Number of trees & 100 \\
\hline Number burn in & 500 \\
\hline Number iteration after burn in & 1000 \\
\hline alpha & 0.95 \\
\hline beta & 2 \\
\hline k & 2 \\
\hline q & 0.9 \\
\hline
\end{tabular}

\subsection{Model Validation}

ROC curves parameters include sensitivity, specificity, NPV, PPV and area under curve (AUC) were used to evaluate the efficiency of Naïve Bayes, RF and BART models. The results of the evaluation of the models in the training and testing stages are shown in Figs. 9 and 10 and Table 3.

According to the results obtained in the training phase, the sensitivity statistics in NB, RF and BART models are $0.76,0.99$ and 0.99 , respectively, which show the high sensitivity of the models used in modelling and their accuracy. The specificity statistics for the NB, RF and BART models were $0.89,0.95$ and 0.90 , respectively. The PPV statistics of $0.74,0.95$ and 0.91 , respectively, and the NPV statistics of $0.77,0.99$ and 0.98 , respectively, were obtained in the NB, RF and BART models, which show the higher accuracy of the models in predicting the non-occurrence points. The results of model evaluation based on AUC showed that the accuracy of NB, RF and BART models is $0.88,0.99$ and 0.89 , respectively, and these models have high accuracy in the training stage.

Evaluation of the models used in the validation phase showed that the sensitivity statistics for NB, RF and BART models were $0.76,0.91$ and 0.94 , respectively, and showed the high sensitivity of the models in flood estimation. The specificity statistics in the Naïve Bayes, RF and BART models were $0.75,0.72$ and 0.78 , respectively. Evaluation of the models based on PPV and NPV statistics showed that this PPV is $0.74,0.75,0.80$, and NPV 0.77, 0.90, and 0.93, respectively, in the Naïve Bayes, RF, and BART models, indicating greater accuracy of the models in predicting non-flood points compared to flood points. For the overall evaluation of the models in the validation phase, the area under the curve (AUC) statistic was used and the results of AUC were obtained for Naïve Bayes, RF and BART models of $0.81,0.85$ and 0.89 , respectively. 
Table 3

The results of evaluating the efficiency of Naïve Bayes, RF and BART models in train and validation stage

\begin{tabular}{|lllllll|}
\hline Models & Stage & \multicolumn{2}{l|}{ Parameters } & & & \\
\cline { 3 - 7 } & & Sensitivity & Specificity & PPV & NPV & AUC \\
Naïve Bayes & Train & 0.76 & 0.89 & 0.87 & 0.78 & 0.88 \\
\cline { 2 - 7 } & Validation & 0.76 & 0.75 & 0.74 & 0.77 & 0.81 \\
\hline \multirow{2}{*}{ RF } & Train & 0.99 & 0.95 & 0.95 & 0.99 & 0.99 \\
\cline { 2 - 7 } & Validation & 0.91 & 0.72 & 0.75 & 0.90 & 0.85 \\
& Train & 0.99 & 0.90 & 0.91 & 0.98 & 0.98 \\
\cline { 2 - 7 } & Validation & 0.94 & 0.78 & 0.80 & 0.93 & 0.89 \\
\hline
\end{tabular}

\subsection{Flood susceptibility modeling results}

After modelling the flood sensitivity using Naive Bayes, RF and BART models and evaluating the efficiency of these models, flood susceptibility was forecasted in the whole watershed. The final map was divided into five different classes, very low, low, moderate, high and very high in terms of susceptibility in ArcGIS software environment and using natural break algorithm (Fig. 11). According to the flood susceptibility maps prediction, flood susceptibility is the highest flood sensitivity around the main river and the areas near the outlet of the watershed, which have a lower altitude. While most of the area, which is generally high altitude, has a very low sensitivity class.

The results of the area and percentage covered by each susceptibility class are shown in Table 4 . According to the results, the highest area of very high susceptibility class is Naive Bayes with $22.11 \mathrm{~km}^{2}$ (10.26\%), RF with $21.23 \mathrm{Km} 2$ (9.85\%) and BART with $19.48 \mathrm{Km} 2$ (9.04\%), respectively. However, the BART model, with $50.5 \mathrm{Km} 2$ (23.5\%), has the largest area with very high and high susceptibility classes.

In order to evaluate the validity of the predicted flood susceptibility maps in relation to the identified flood points in the study area, the frequency ratio (FR) was used (Fig. 9). According to the results of Fig. 12, it is observed that the highest frequency ratio is in very high and high classes, which indicates the appropriate prediction of the models used for flood-susceptibility areas, however, the FR in the BART model in the very high class is much higher than the other two models, which indicates a more accurate prediction of flood susceptibility in this area.

Table 4. The percent and area of each flood susceptibility classes. 


\begin{tabular}{|lllllll|}
\hline Susceptibility class & \multicolumn{2}{l}{ Naïve Bayes } & \multicolumn{3}{c}{ RF } & \multicolumn{3}{c|}{ BART } \\
\cline { 2 - 7 } & Area $\left(\mathrm{km}^{2}\right)$ & Area $(\%)$ & Area $\left(\mathrm{km}^{2}\right)$ & Area $(\%)$ & Area $\left(\mathrm{km}^{2}\right)$ & Area (\%) \\
\hline Very low & 121.85 & 56.52 & 112.32 & 52.10 & 106 & 49.17 \\
\hline Low & 31.53 & 14.62 & 33.24 & 15.42 & 28.39 & 13.17 \\
\hline Moderate & 21.67 & 10.05 & 31.04 & 14.40 & 30.65 & 14.22 \\
\hline High & 18.44 & 8.55 & 17.77 & 8.24 & 31.08 & 14.42 \\
\hline Very High & 22.11 & 10.26 & 21.23 & 9.85 & 19.48 & 9.04 \\
\hline 4. Explanatory Variable Importance & & & \\
\hline
\end{tabular}

The results of the importance of the independent (i.e. input) variables used to model the flood susceptibility using the three Naïve Bayes, RF and BART models are shown in Fig. 13. Based on the results, it is clear that in the three models used, the variables have different effects on determining the flood susceptibility. However, it is clear the variables of altitude and distance from the river in all three models were more important than other variables in modelling.

Due to the importance of 4 variables altitude, distance from the river, distance from road and rainfall on flood susceptibility in BART model, the graph of minor changes of these 4 variables in flood susceptibility was investigated (Fig. 14). Based on the results of partial effects in altitude, it is determined that with increasing altitude, the flood susceptibility decreases, so that the highest sensitivity to floods is at an altitude of 1400 meters, which is close to the outlet of the watershed and with increasing altitude, the susceptibility is reduced and indicates the inverse relationship between the altitude variable and the flood susceptibility. A study of the distance from river variable shows that distances less than $\mathbf{5 0 0}$ meters have a high susceptibility to floods and from 500 meters upwards the trend of flood susceptibility has been decreasing so that at distances of 1000-1500 meters probability flood susceptibility is low and constant. In the distance from road variable, with increasing distance from the road, the sensitivity to flood has a decreasing trend. The most sensitive areas are less than 1000 meters from the road. A study of the effect of rainfall variable on flood sensitivity shows that areas with 450 to $500 \mathrm{~mm}$ of rainfall are more sensitive than flood and with increasing rainfall, the susceptibility decreases so that from rainfall 550 to $650 \mathrm{~mm}$, the susceptibility is low and constant.

\section{Discussion}

Performance evaluation of Naïve Bayes, RF, and BART models showed that the BART model performed best in the validation stage in terms of predicting flood susceptibility. The BART model is a nonparametric Bayesian regression approach that uses consistent basic random elements. Bayesian Additive Regression Trees (BART) provides a flexible way to fit a variety of regression models while avoiding strong parametric assumptions (Hill et al. 2020). The tree ensemble model is supported by an uncertainty framework in the Bayesian inferential framework and provides a principled approach to regulation through previous specifications (Pratola and Higdon 2016; Sparapani et al. 2016). This model uses a 
non-parametric tree aggregation model to allow flexibility of the average structure of a regression. But it also has the advantages of a Bayesian inferential framework given the amount of uncertainty and its regulation through calibrated data locations (Sparapani et al. 2016; Hill et al. 2020).

One of the main advantages of the BART model is the capacity to form inference on numerous features of the survival distribution directly from the posterior samples. As a Bayesian model, BART consists of a set of priors for the construction and the leaf parameters and a possibility for data in the terminal nodes (Pratola and Higdon 2016; Sparapani et al. 2016). The object of the priors is to afford regularization, limiting any single regression tree from dominating the total fit. Many $M L$ models suffer from missing data problems. BART model has a specialty that provides the user to straight designation missing covariate data within the BART structure. This method combines missing data indicators into the training data set and supports for divisions on the missing indicators, guiding to raised efficiency under a pattern ensemble model structure (Hill et al. 2020). Various researchers (Choubin et al. 2019; Arabameri et al. 2020; Shahabi et al. 2020) have also concluded in the study of flood susceptibility that ensemble models perform better than individual models and they explained that the ensemble models use a combination of several models, which reduces the prediction error of the model using this approach and with ensemble different models, the limitations of each model can be reduced and more acceptable results can be obtained.

Determining the importance of independent variables in flood susceptibility modeling in the Kan watershed showed that altitude, distance from river, distance from road and rainfall variables are important factors affecting flood susceptibility in this region. A study of altitude variable shows that low altitudes, which are often at the outlet of watersheds, are highly susceptible to flooding, which is consistent with the findings of Khosravi et al. (2019), Pham et al., (2020a).

Distance from river is another important factor in flood susceptibility in the Kan watershed, and the results indicate the sensitivity of areas close to the river. Ahmadlou et al., (2019) showed in their studies that areas 500-1000 meters from the river are highly sensitive to flooding. Given that the flood-prone areas are located near the river and the reason is due to rise of flow from the river channels (Choubin et al. 2019; Darabi et al. 2019), in the Kan watershed, due to lack of observance of riverbed and river boundaries, several restaurants and villas have been built in the areas near the river, and due to the presence of more orchard in the river area, has led to the obstruction of flow in these areas and has increased the sudden release of flood current. Invasion of the river boundaries and the create of orchard in it, in addition to causing financial damage to the residents of the area, also by blocking the flow in sections such as tunnels, will cause secondary floods and intensify the damage to the people and downstream areas.

Another factor affecting the flood susceptibility in the Kan watershed is the distance from road, according to the results, it was found that areas close to the road are highly sensitive to flooding. Construction and crate of communication roads will increase the runoff and runoff speed because it will reduce the area of 
the existing surface to absorb rainfall and thus increase the sensitivity to flooding in these areas (Tehrany et al. 2019b; Zhao et al. 2019).

The study of the rainfall factor indicates that areas with less rainfall are highly susceptible to flood, which are mainly areas close to the outlet of the Kan watershed. Due to the mountainous nature of the region, most of the precipitation in the upstream areas of the Kan watershed is snow, so in these areas the possibility of infiltration is higher. In addition, precipitation in the downstream areas is in the form of storms and these storms are usually more severe in the autumn and causes the river inundation and flooding.

\section{Conclusion}

Among the existing natural disasters, floods are one of the most frequent and destructive dangers that cause a lot of damage. In order to investigate and analyze floods, different methods have been studied by different researchers, considering that the two components of time and accuracy in reducing risk and primary warning play a key role in modeling natural hazards, therefore, different methods and algorithms should be considered in terms of efficiency and reliability to select the most suitable ones.

In this study, the Bayesian based model (Naïve Bayes), regression tree type model (Random Forest) and ensemble type model (Bayesian Additive Regression Tree - BART) were developed to predict flood susceptibility in the Kan watershed. A total of 15 explanatory (i.e. model input) variables were used after multi-collinearity analyses as independent variables and 118 flood locations and 115 non-flood locations after field surveys and the use of available information as a dependent variable for flood modeling.

The validation results obtained for flood susceptibility modeling showed that the Naïve Bayes, RF and BART models all have a good predictive performance. However, the new BART model has the higher prediction accuracy than the Naïve Bayes and RF models. This is due to the fact that it uses features of both methods in the ensemble setting.

The analysis of the importance of explanatory variables showed that the effect of independent variables is different in each model. However, the altitude and distance from the river were more important than other variables in all three models. Due to the partial effect in these variables, it was found that low-height areas and areas close to the river are more susceptible to flooding.

The Kan watershed is close to the city of Tehran and the pleasant climate of this tourist area has caused that its riverbanks are occupied without any regulations and many constructions that have been carried out. These areas receive a large number of tourists in spring and summer and hence are strongly affected by the floods. It is therefore necessary to provide flood hazard maps for the region. The results of this research can be used, as baseline map in development projects and proper management to determine the floodplain area to prevent construction in high-risk areas to reduce the vulnerability.

\section{Declarations}


Author Contributions: Saeid Janizadeh acquired the data; Saeid Janizadeh and Mehdi Vafakhah conceptualized and performed the analysis; Saeid Janizadeh wrote the manuscript and discussion, and analyzed the data; Mehdi Vafakhah, Zoran Kapelan and Naghmeh Mobarghaee Dinan provided technical sights, as well as edited, restructured, and professionally optimized the manuscript. All authors discussed the results and edited the manuscript. All authors have read and agreed to the published version of the manuscript.

Ethical Approval: We confirm that this manuscript has not been published elsewhere and is not under consideration by another journal.

Consent to Participate: All authors have participated the manuscript and agree with submission to Water Resources Management.

Consent to Publish: All authors have approved the publication of this manuscript in the Water Resources Management Journal.

Availability of data and materials: We have no permission to release data and codes.

Funding: The authors received no specific funding for this work.

Acknowledgments: We acknowledge Tarbiat Modares University's support for this work.

Conflicts of Interest: The authors declare no conflict of interest.

\section{References}

1. Ahmadlou M, Karimi M, Alizadeh S et al (2019) Flood susceptibility assessment using integration of adaptive network-based fuzzy inference system (ANFIS) and biogeography-based optimization (BBO) and BAT algorithms (BA). Geocarto Int 34:1252-1272

2. Al-Abadi AM (2018) Mapping flood susceptibility in an arid region of southern Iraq using ensemble machine learning classifiers: a comparative study. Arab J Geosci 11:218

3. Al-Juaidi AEM, Nassar AM, Al-Juaidi OEM (2018) Evaluation of flood susceptibility mapping using logistic regression and GIS conditioning factors. Arab J Geosci 11:765

4. Arabameri A, Saha S, Chen W et al (2020) Flash flood susceptibility modelling using functional tree and hybrid ensemble techniques. J Hydrol 125007

5. Bui DT, Panahi M, Shahabi $\mathrm{H}$ et al (2018) Novel hybrid evolutionary algorithms for spatial prediction of floods. Sci Rep 8:15364

6. Chapi K, Singh VP, Shirzadi A et al (2017) A novel hybrid artificial intelligence approach for flood susceptibility assessment. Environ Model Softw 95:229-245

7. Chen W, Li Y, Xue W et al (2020) Modeling flood susceptibility using data-driven approaches of na $\{\backslash \backslash \backslash\}$ ve bayes tree, alternating decision tree, and random forest methods. Sci Total Environ 
701:134979

8. Choubin B, Moradi E, Golshan M et al (2019) An ensemble prediction of flood susceptibility using multivariate discriminant analysis, classification and regression trees, and support vector machines. Sci Total Environ 651:2087-2096

9. Cook A, Merwade V (2009) Effect of topographic data, geometric configuration and modeling approach on flood inundation mapping. J Hydrol 377:131-142

10. Costache R (2019) Flash-flood Potential Index mapping using weights of evidence, decision Trees models and their novel hybrid integration. Stoch Environ Res Risk Assess 33:1375-1402

11. Costache R, Bui DT (2020) Identification of areas prone to flash-flood phenomena using multiplecriteria decision-making, bivariate statistics, machine learning and their ensembles. Sci Total Environ 712:136492

12. Darabi H, Choubin $B$, Rahmati $O$ et al (2019) Urban flood risk mapping using the GARP and QUEST models: A comparative study of machine learning techniques. J Hydrol 569:142-154

13. Delkash M, Al-Faraj FAM, Scholz M (2014) Comparing the export coefficient approach with the soil and water assessment tool to predict phosphorous pollution: the Kan watershed case study. Water Air Soil Pollut 225:2122

14. Frattini P, Crosta G, Carrara A (2010) Techniques for evaluating the performance of landslide susceptibility models. Eng Geol 111:62-72

15. Heidari A (2014) Flood vulnerability of the K arun R iver S ystem and short-term mitigation measures. $\mathrm{J}$ flood risk Manag 7:65-80

16. Hill J, Linero A, Murray J (2020) Bayesian additive regression trees: A review and look forward. Annu Rev Stat Its Appl 7:251-278

17. Hong H, Panahi M, Shirzadi A et al (2018) Flood susceptibility assessment in Hengfeng area coupling adaptive neuro-fuzzy inference system with genetic algorithm and differential evolution. Sci Total Environ 621:1124-1141

18. Hosseini FS, Choubin B, Mosavi A et al (2020) Flash-flood hazard assessment using ensembles and Bayesian-based machine learning models: application of the simulated annealing feature selection method. Sci Total Environ 711:135161

19. Janizadeh S, Avand M, Jaafari A et al (2019) Prediction Success of Machine Learning Methods for Flash Flood Susceptibility Mapping in the Tafresh Watershed. Iran Sustainability 11:5426

20. Kapelner A, Bleich J (2013) bartMachine: Machine learning with Bayesian additive regression trees. arXiv Prepr arXiv13122171

21. Khosravi K, Pham BT, Chapi K et al (2018) A comparative assessment of decision trees algorithms for flash flood susceptibility modeling at Haraz watershed, northern Iran. Sci Total Environ 627:744755

22. Khosravi K, Pourghasemi HR, Chapi K, Bahri M (2016) Flash flood susceptibility analysis and its mapping using different bivariate models in Iran: a comparison between Shannon's entropy, 
statistical index, and weighting factor models. Environ Monit Assess 188:656

23. Khosravi K, Shahabi H, Pham BT et al (2019) A comparative assessment of flood susceptibility modeling using Multi-Criteria Decision-Making Analysis and Machine Learning Methods. J Hydrol 573:311-323

24. Liaw A, Wiener M, others (2002) Classification and regression by randomForest. R news 2:18-22

25. Liu R, Chen Y, Wu J et al (2016) Assessing spatial likelihood of flooding hazard using na\{\"\i\}ve Bayes and GIS: a case study in Bowen Basin, Australia. Stoch Environ Res risk Assess 30:15751590

26. Mahmoud SH, Gan TY (2018) Multi-criteria approach to develop flood susceptibility maps in arid regions of Middle East. J Clean Prod 196:216-229

27. Miles J (2014) Tolerance and variance inflation factor. Wiley StatsRef Stat Ref Online

28. Molinos-Senante M, Hernández-Sancho F, Sala-Garrido R (2011) Cost-benefit analysis of waterreuse projects for environmental purposes: A case study for Spanish wastewater treatment plants. J Environ Manage 92:3091-3097

29. Papaioannou G, Vasiliades L, Loukas A (2015) Multi-criteria analysis framework for potential flood prone areas mapping. Water Resour Manag 29:399-418

30. Perera EDP, Hiroe A, Shrestha D et al (2015) Community-based flood damage assessment approach for lower West Rapti River basin in Nepal under the impact of climate change. Nat Hazards 75:669699

31. Pham BT, Avand M, Janizadeh S et al (2020a) GIS Based Hybrid Computational Approaches for Flash Flood Susceptibility Assessment. Water 12:683

32. Pham BT, Phong T, Van, Nguyen HD et al (2020b) A Comparative Study of Kernel Logistic Regression, Radial Basis Function Classifier, Multinomial Na\{\"\i\}ve Bayes, and Logistic Model Tree for Flash Flood Susceptibility Mapping. Water 12:239

33. Pratola MT, Higdon DM (2016) Bayesian additive regression tree calibration of complex highdimensional computer models. Technometrics 58:166-179

34. Rahmati O, Pourghasemi HR, Zeinivand H (2016) Flood susceptibility mapping using frequency ratio and weights-of-evidence models in the Golastan Province, Iran. Geocarto Int 31:42-70

35. Rish I, others (2001) An empirical study of the naive Bayes classifier. In: IJCAI 2001 workshop on empirical methods in artificial intelligence. pp 41-46

36. Shafapour Tehrany M, Shabani F, Neamah Jebur M et al (2017) GIS-based spatial prediction of flood prone areas using standalone frequency ratio, logistic regression, weight of evidence and their ensemble techniques. Geomatics, Nat Hazards Risk 8:1538-1561

37. Shafizadeh-Moghadam H, Valavi R, Shahabi H et al (2018) Novel forecasting approaches using combination of machine learning and statistical models for flood susceptibility mapping. J Environ Manage 217:1-11 
38. Shahabi H, Shirzadi A, Ghaderi K et al (2020) Flood detection and susceptibility mapping using sentinel-1 remote sensing data and a machine learning approach: Hybrid intelligence of bagging ensemble based on k-nearest neighbor classifier. Remote Sens 12:266

39. Sparapani RA, Logan BR, McCulloch RE, Laud PW (2016) Nonparametric survival analysis using Bayesian additive regression trees (BART). Stat Med 35:2741-2753

40. Tang X, Li J, Liu M et al (2020) Flood susceptibility assessment based on a novel random Na\{\"\i\}ve Bayes method: A comparison between different factor discretization methods. Catena 190:104536

41. Tang Z, Yi S, Wang C, Xiao Y (2018) Incorporating probabilistic approach into local multi-criteria decision analysis for flood susceptibility assessment. Stoch Environ Res risk Assess 32:701-714

42. Tehrany MS, Jones S, Shabani F (2019a) Identifying the essential flood conditioning factors for flood prone area mapping using machine learning techniques. Catena 175:174-192

43. Tehrany MS, Kumar L (2018) The application of a Dempster-Shafer-based evidential belief function in flood susceptibility mapping and comparison with frequency ratio and logistic regression methods. Environ Earth Sci 77:490

44. Tehrany MS, Kumar L, Shabani F (2019b) A novel GIS-based ensemble technique for flood susceptibility mapping using evidential belief function and support vector machine: Brisbane, Australia. PeerJ 7:e7653

45. Tehrany MS, Pradhan B, Jebur MN (2014) Flood susceptibility mapping using a novel ensemble weights-of-evidence and support vector machine models in GIS. J Hydrol 512:332-343

46. Tehrany MS, Pradhan B, Mansor S, Ahmad N (2015) Flood susceptibility assessment using GISbased support vector machine model with different kernel types. Catena 125:91-101

47. Vafakhah M, Loor SMH, Pourghasemi $H$, Katebikord A (2020) Comparing performance of random forest and adaptive neuro-fuzzy inference system data mining models for flood susceptibility mapping. Arab J Geosci 13:417

48. Vetrivel A, Gerke M, Kerle N et al (2018) Disaster damage detection through synergistic use of deep learning and 3D point cloud features derived from very high resolution oblique aerial images, and multiple-kernel-learning. ISPRS J Photogramm Remote Sens 140:45-59

49. Woodward M, Kapelan Z, Gouldby B (2014) Adaptive flood risk management under climate change uncertainty using real options and optimization. Risk Anal 34:75-92

50. Yariyan P, Janizadeh S, Van Phong T et al (2020) Improvement of Best First Decision Trees Using Bagging and Dagging Ensembles for Flood Probability Mapping. Water Resour Manag 1-17

51. Yesilnacar E, Topal T (2005) Landslide susceptibility mapping: a comparison of logistic regression and neural networks methods in a medium scale study, Hendek region (Turkey). Eng Geol 79:251266

52. Zhang H (2004) The Optimality of Naive Bayes, 2004. Am Assoc Artif Intell (www aaai org)

53. Zhao G, Pang B, Xu Z et al (2019) Assessment of urban flood susceptibility using semi-supervised machine learning model. Sci Total Environ 659:940-949 
Figures
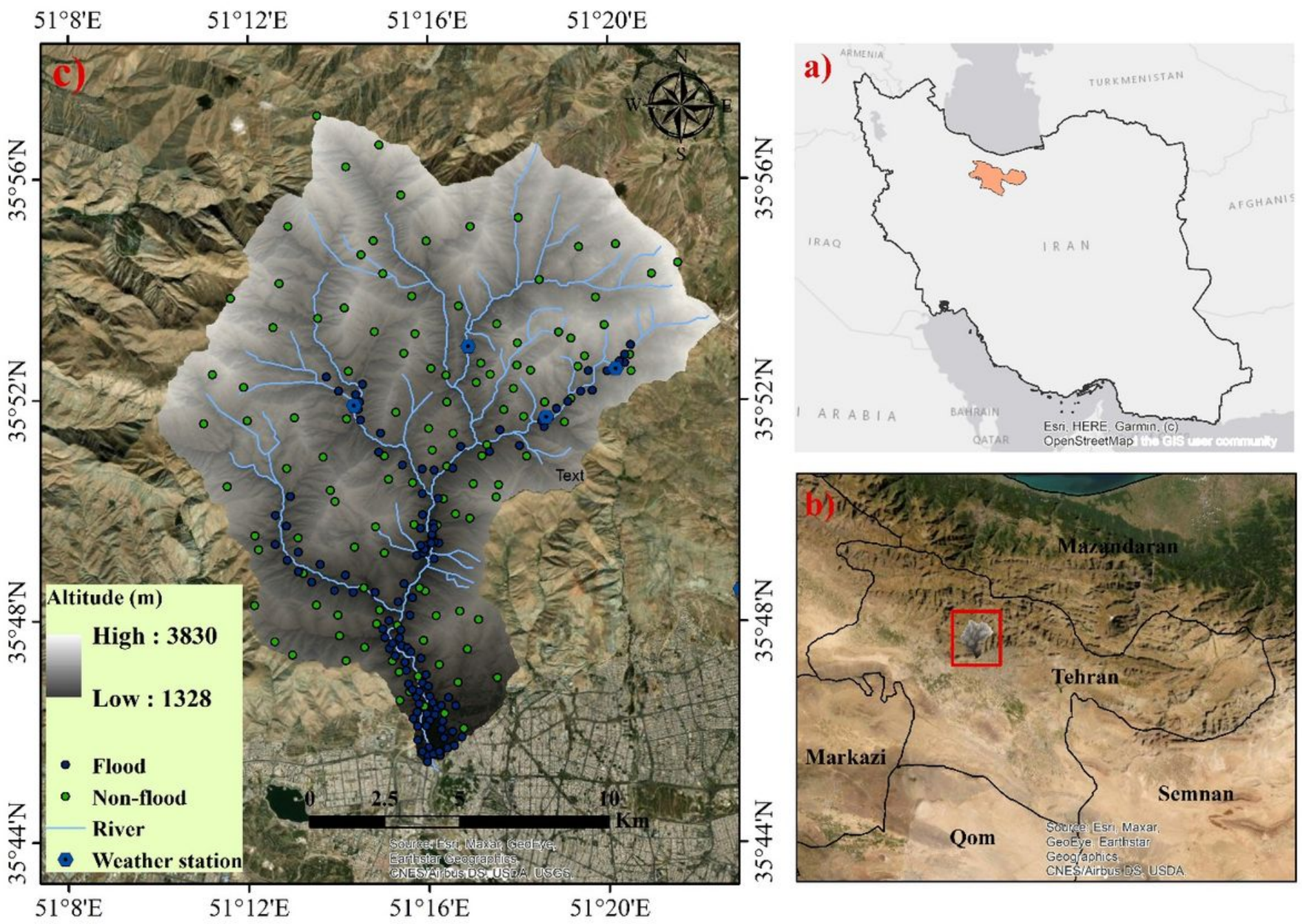

\section{Figure 1}

Location of case study a) Iran country b) Tehran Province and c) Kan watershed 


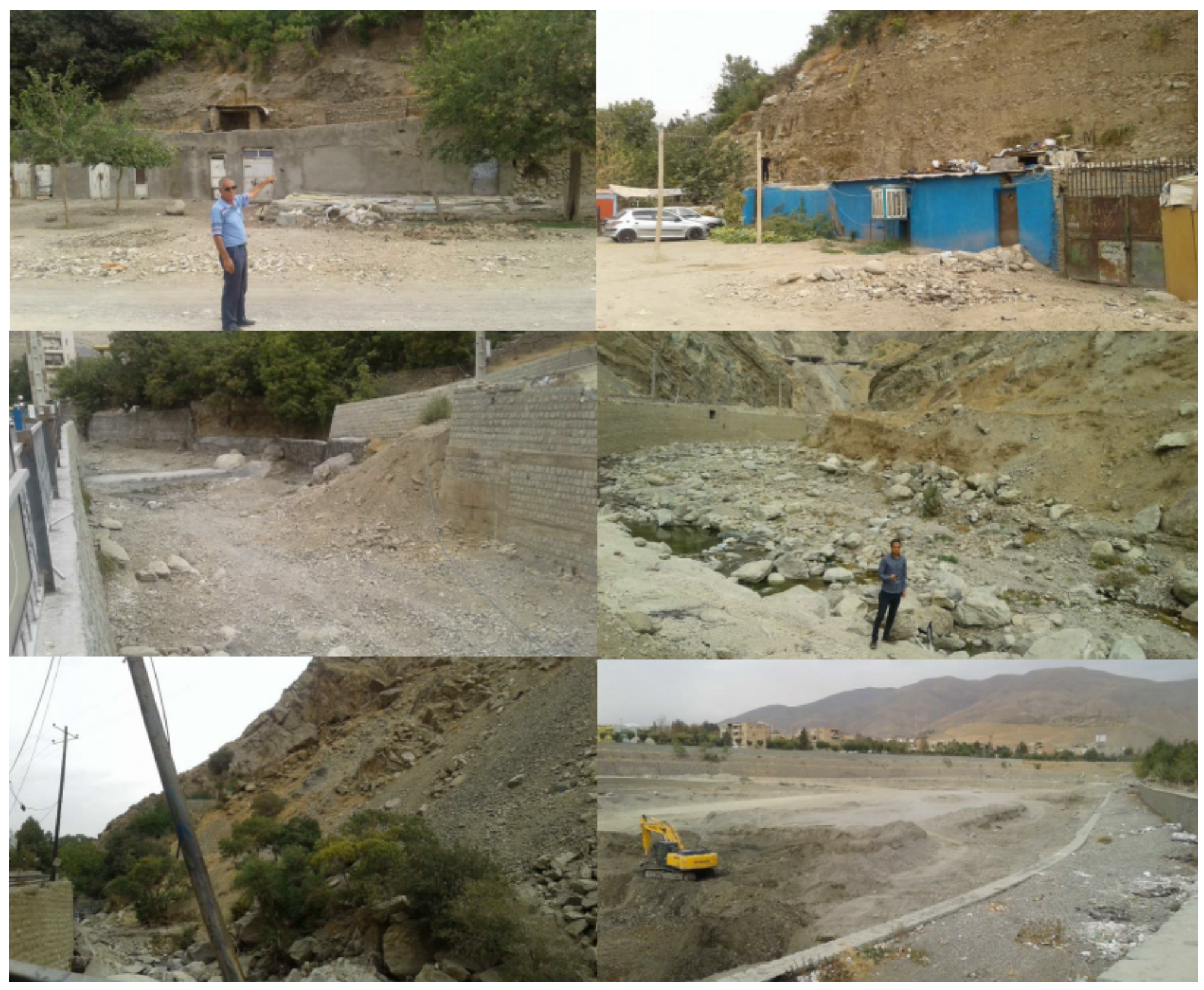

Figure 2

Example of a flood location in the Kan watershed 


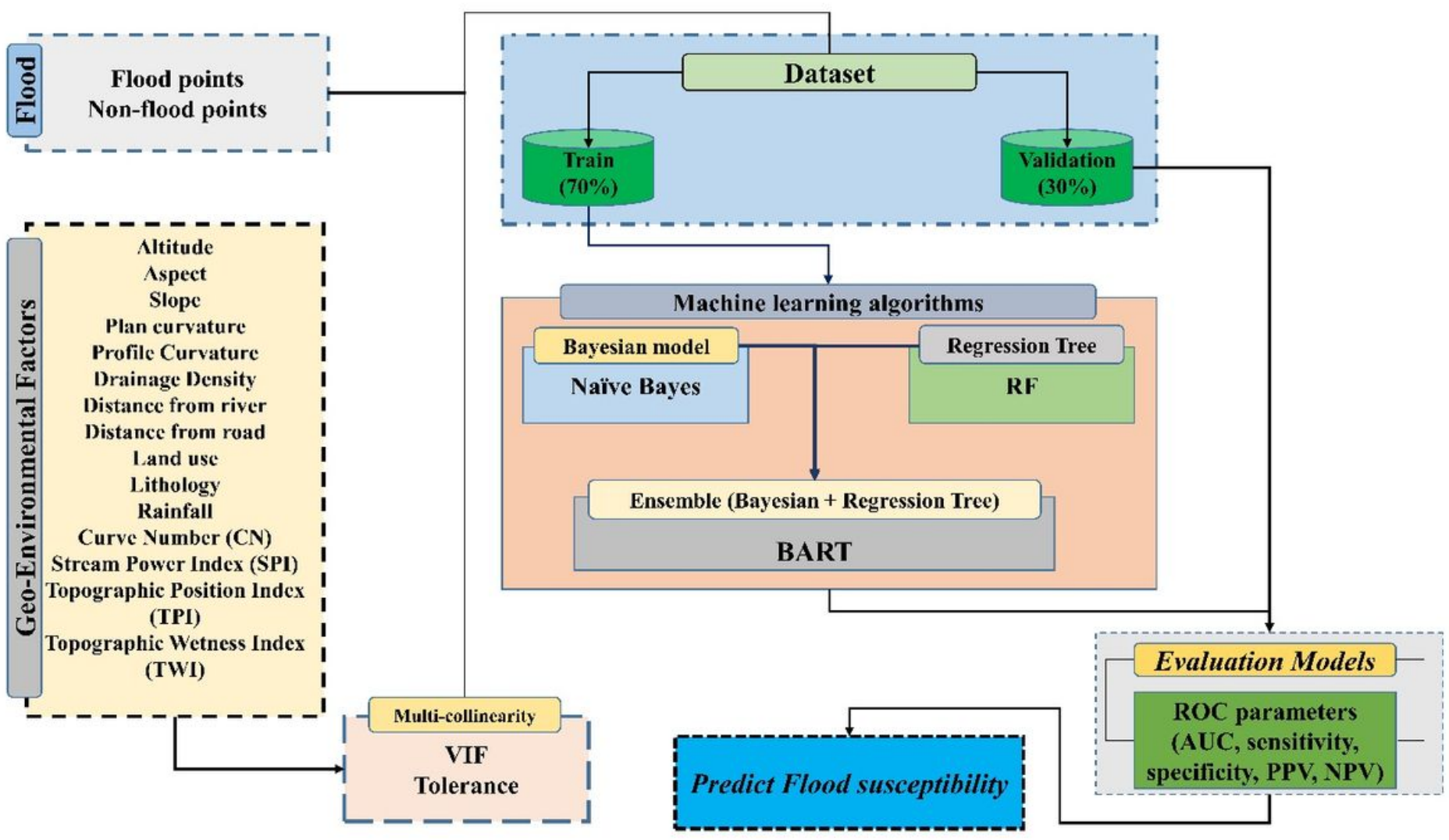

\section{Figure 3}

Methodological flowchart of research steps 

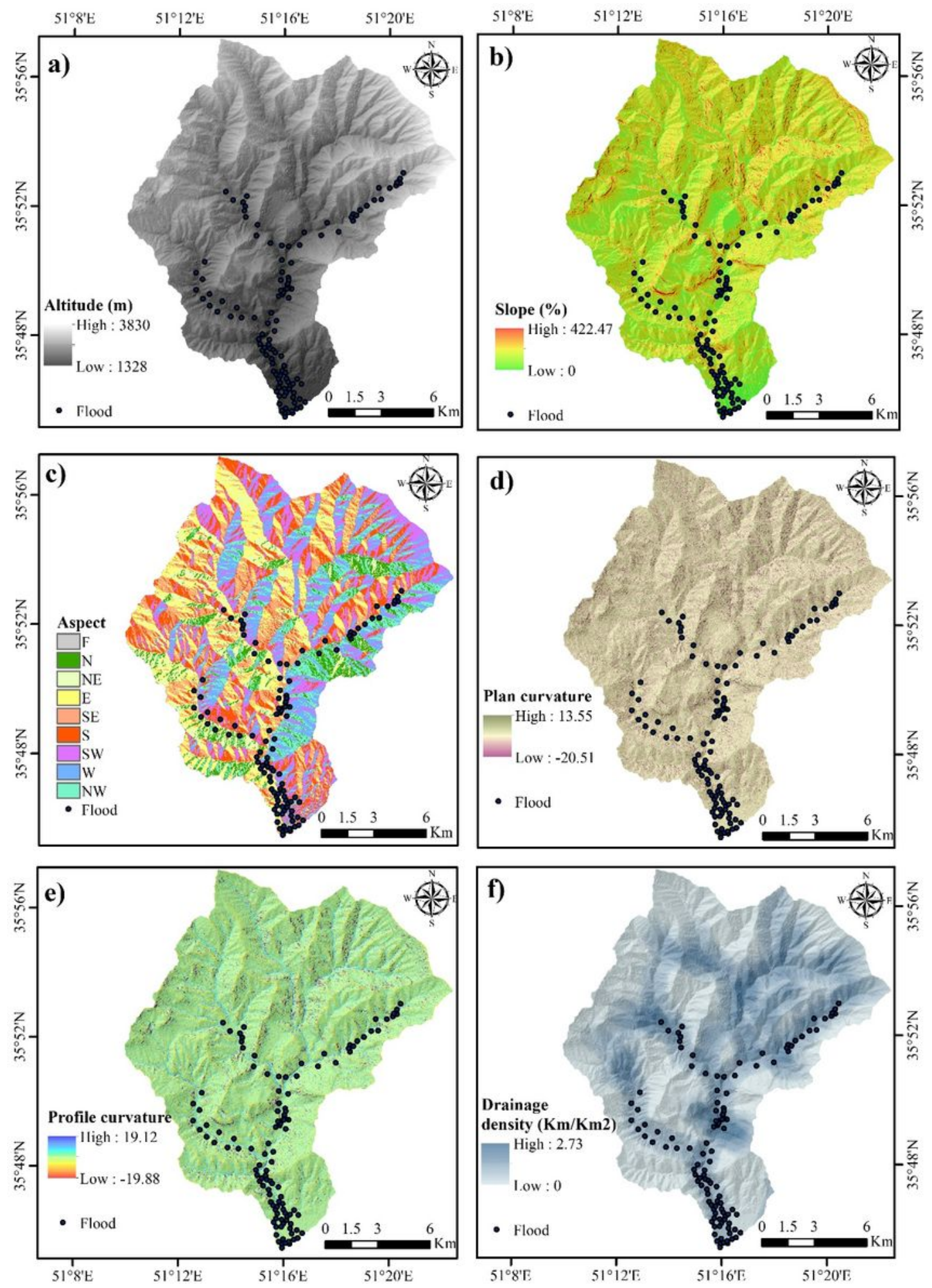

Figure 4

Flood conditioning factors: a) altitude, b) aspect, c) slope, d) plan curvature, e) profile curvature, f) drainage density 

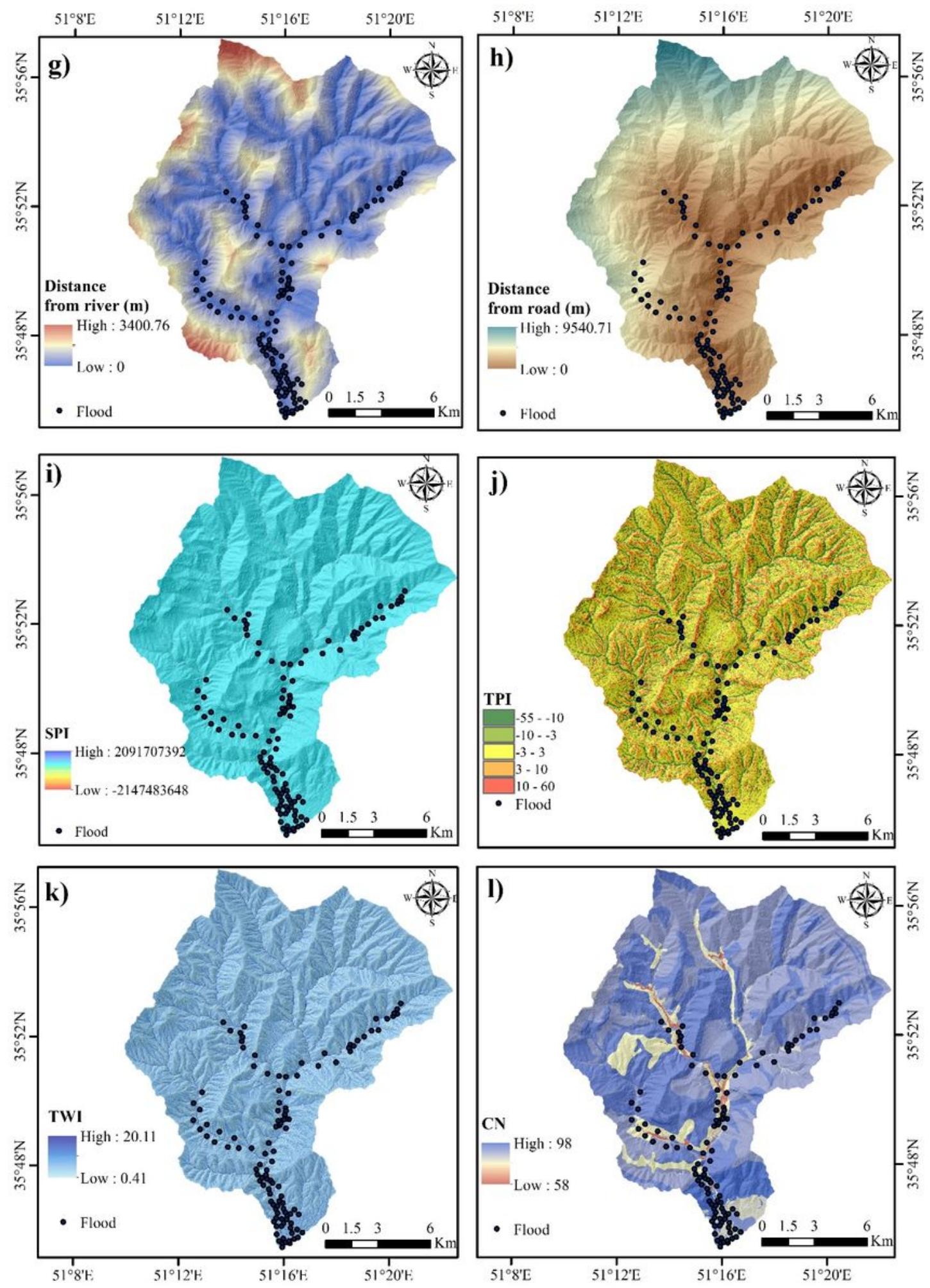

Figure 5

Flood conditioning factors: g) distance form river, h) distance from road, i) SPI, j) TWI, k) TPI, I) CN 



Figure 6

Flood conditioning factors: land use, n) lithology and o) annual rainfall 


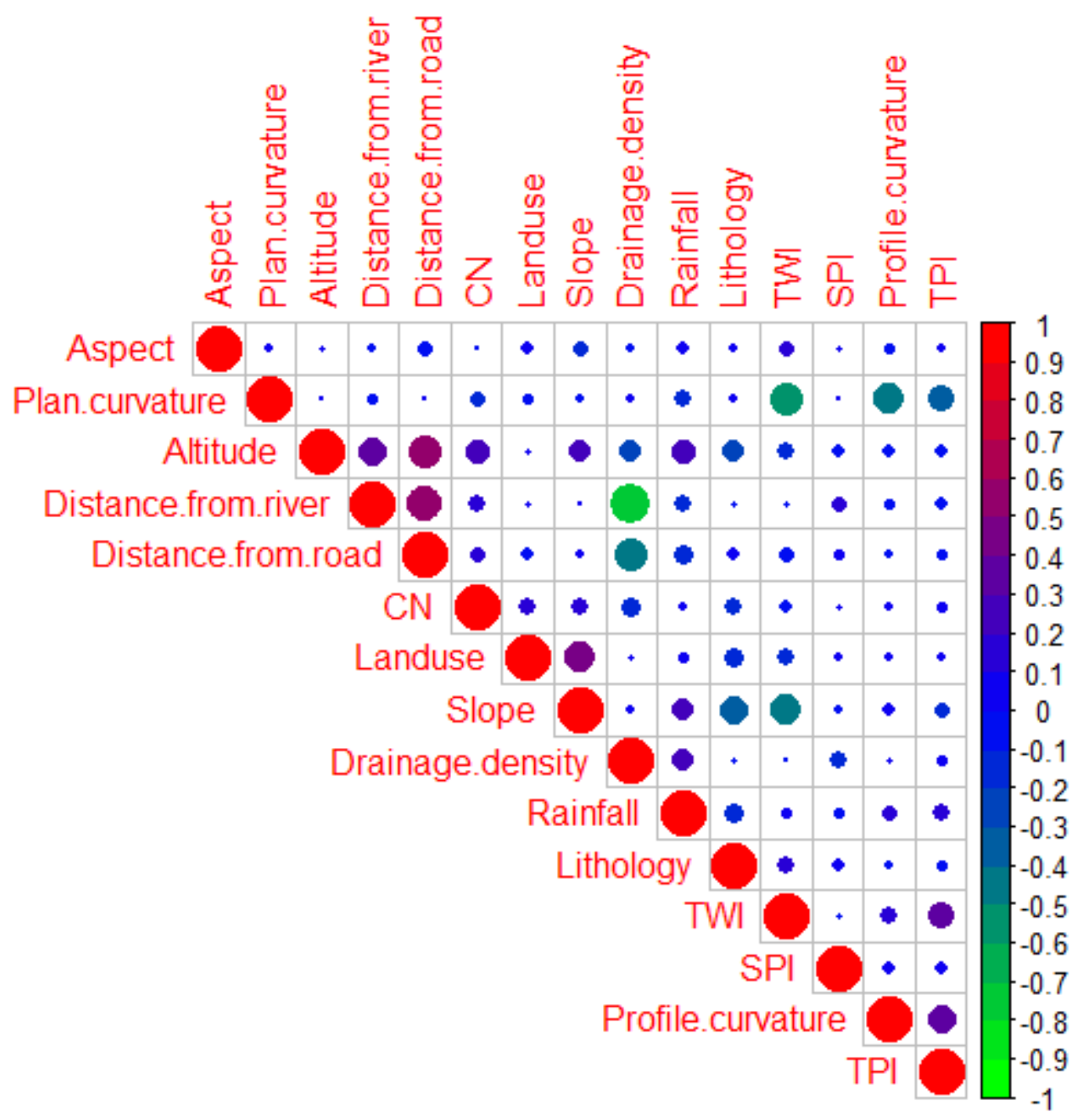

Figure 7

Correlation analyses between independent variables 
Sigsq Estimates over MCMC Iteration
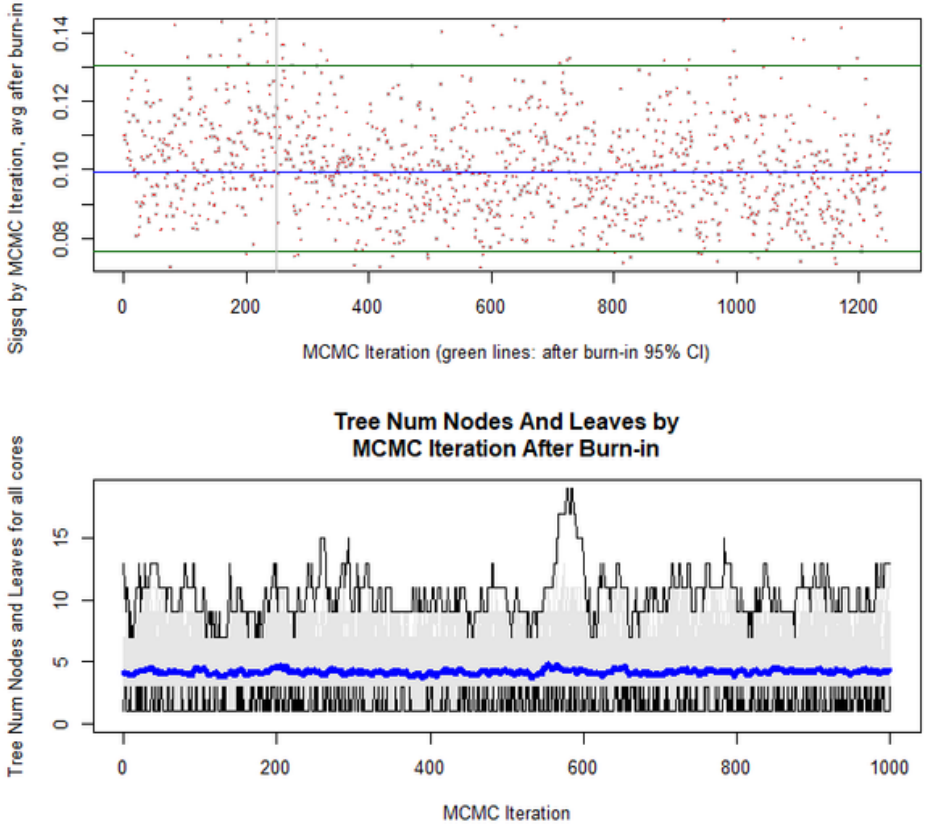

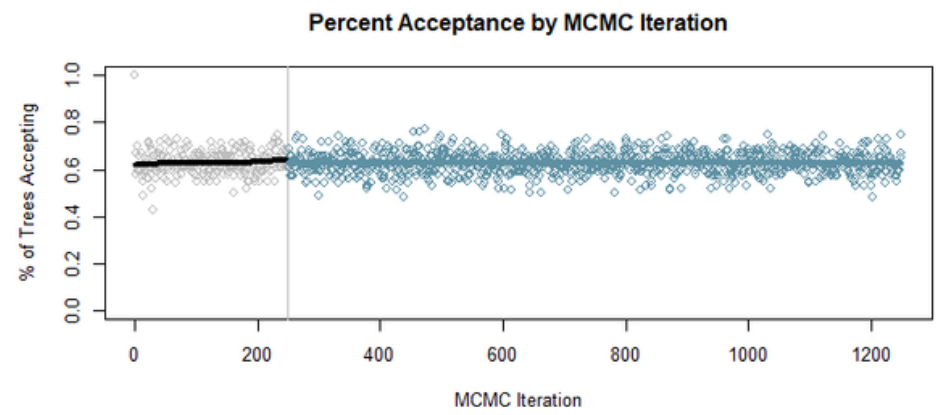

Tree Depth by MCMC Iteration After Burn-in



\section{Figure 8}

The result of BART model in flood susceptibility
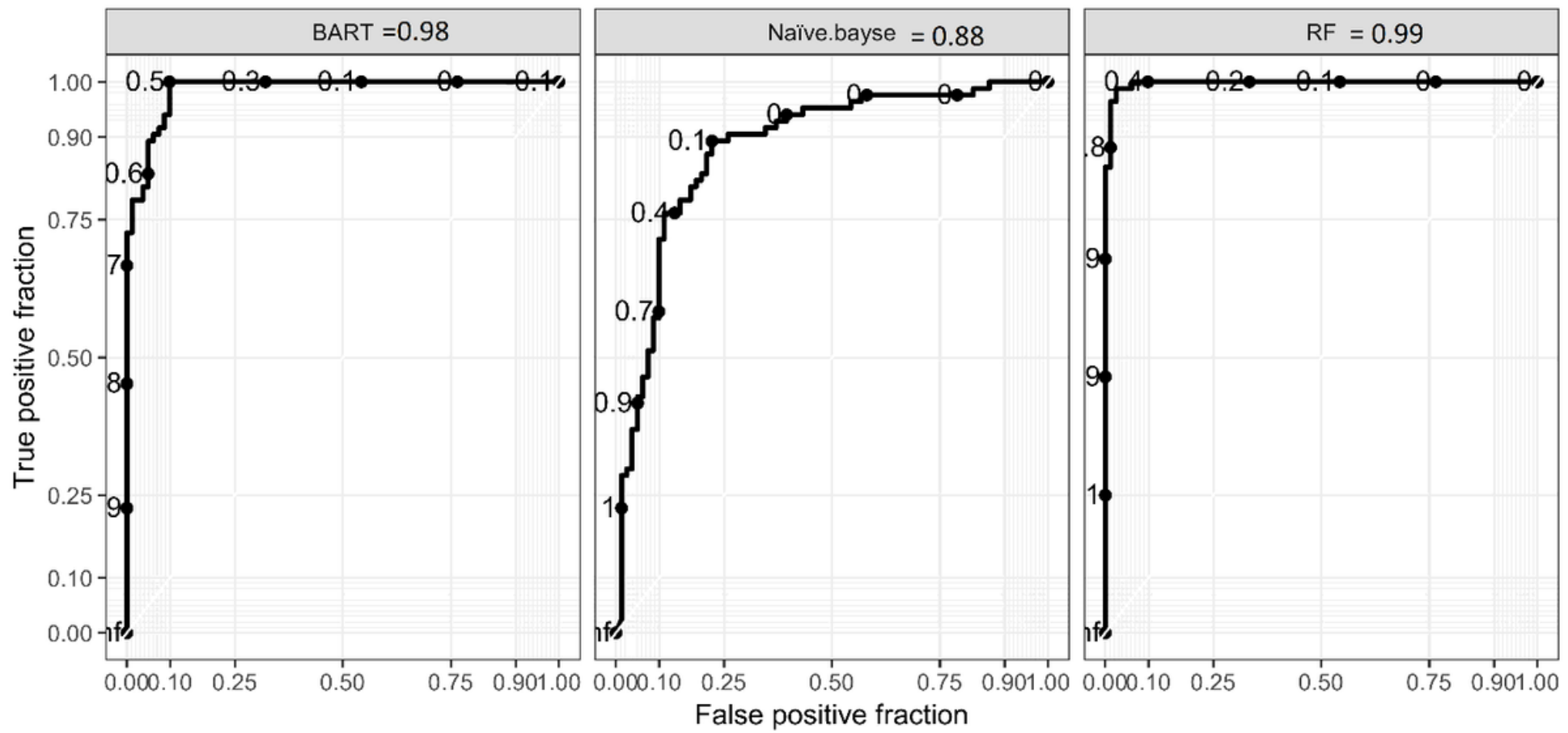

\section{Figure 9}

The ROC curve analysis for Naïve Bayes, RF and BART models using the train dataset 


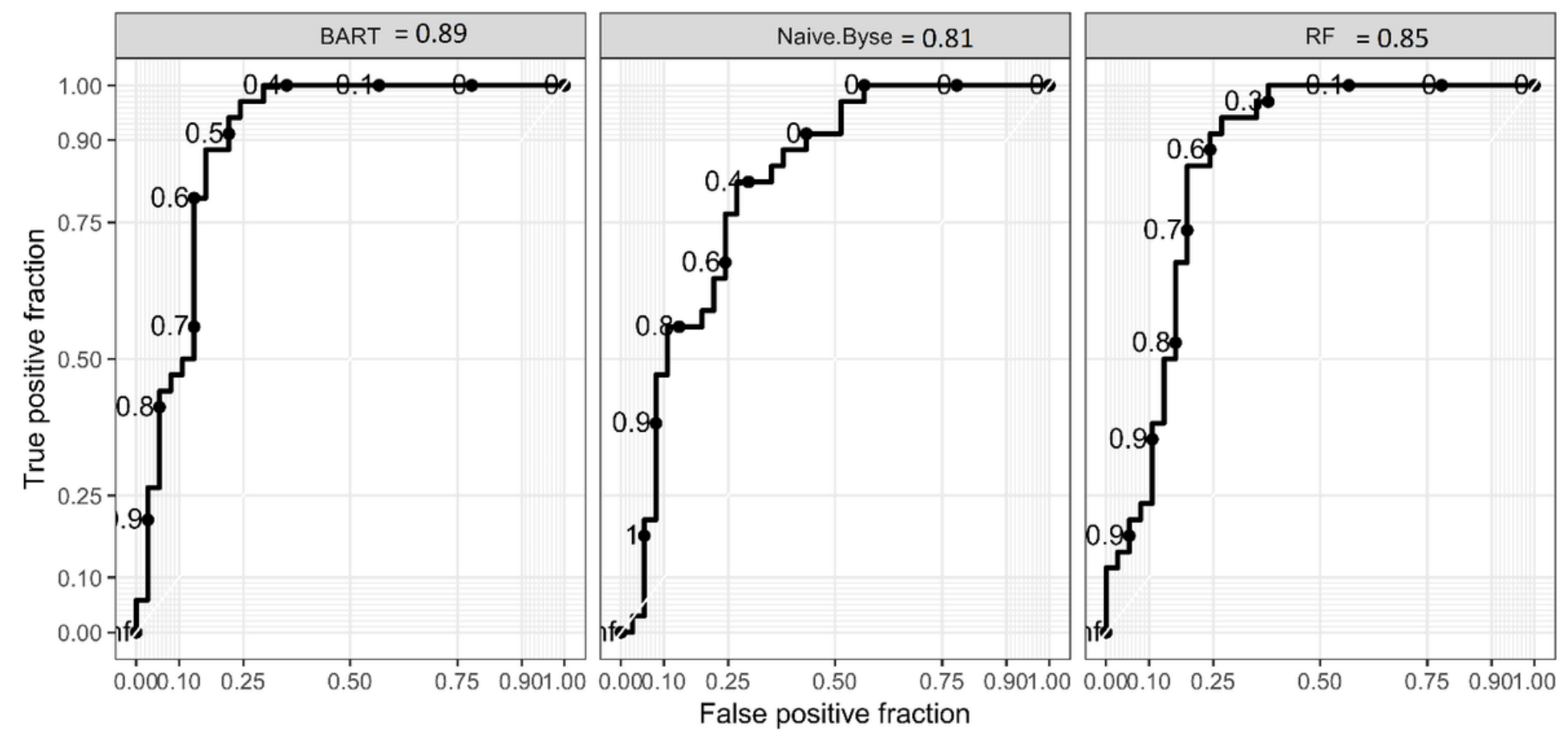

Figure 10

The ROC curve analysis for Naïve Bayes, RF and BART models using the testing dataset. 

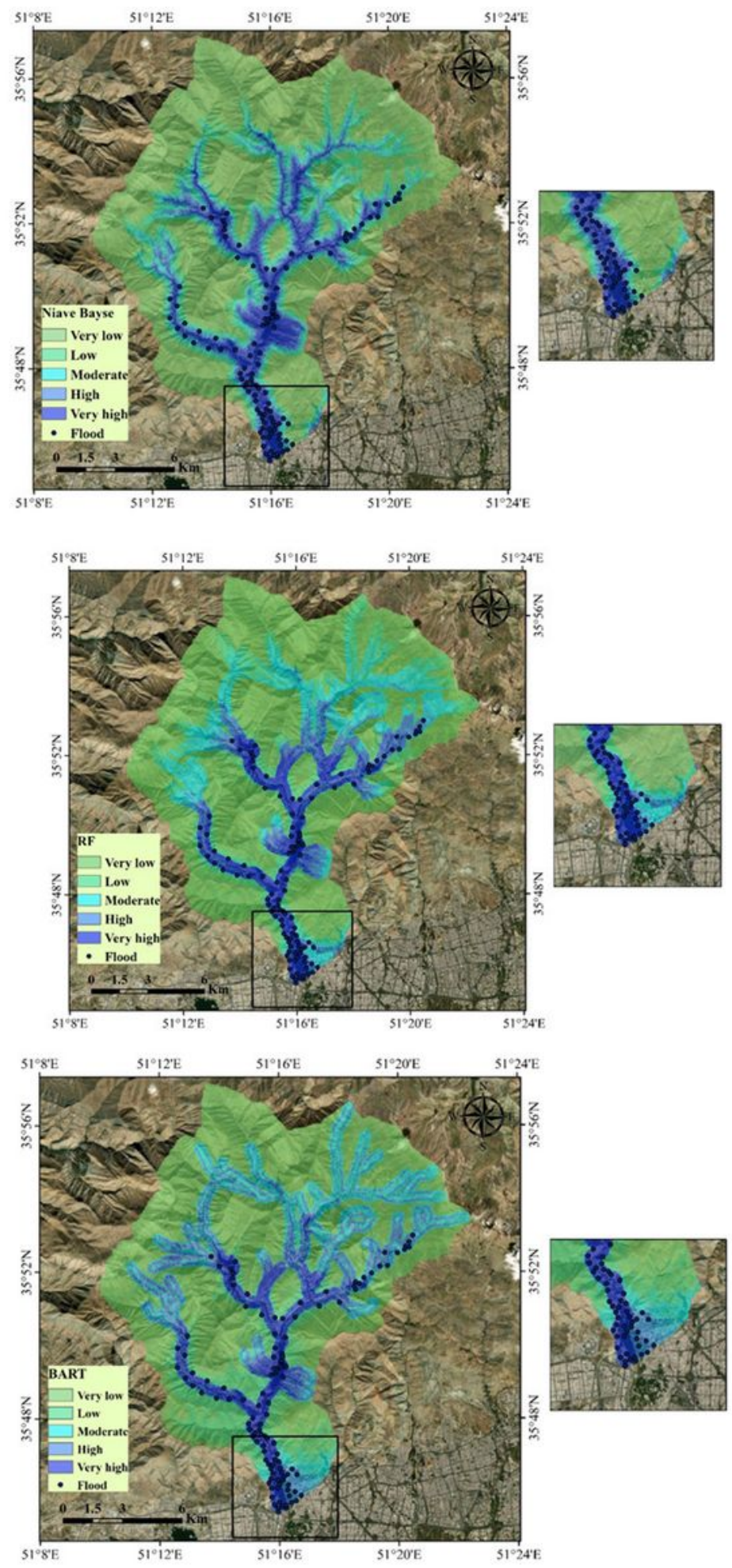

Figure 11

Flood susceptibility map using the Naïve Bayes, RF and BART models 


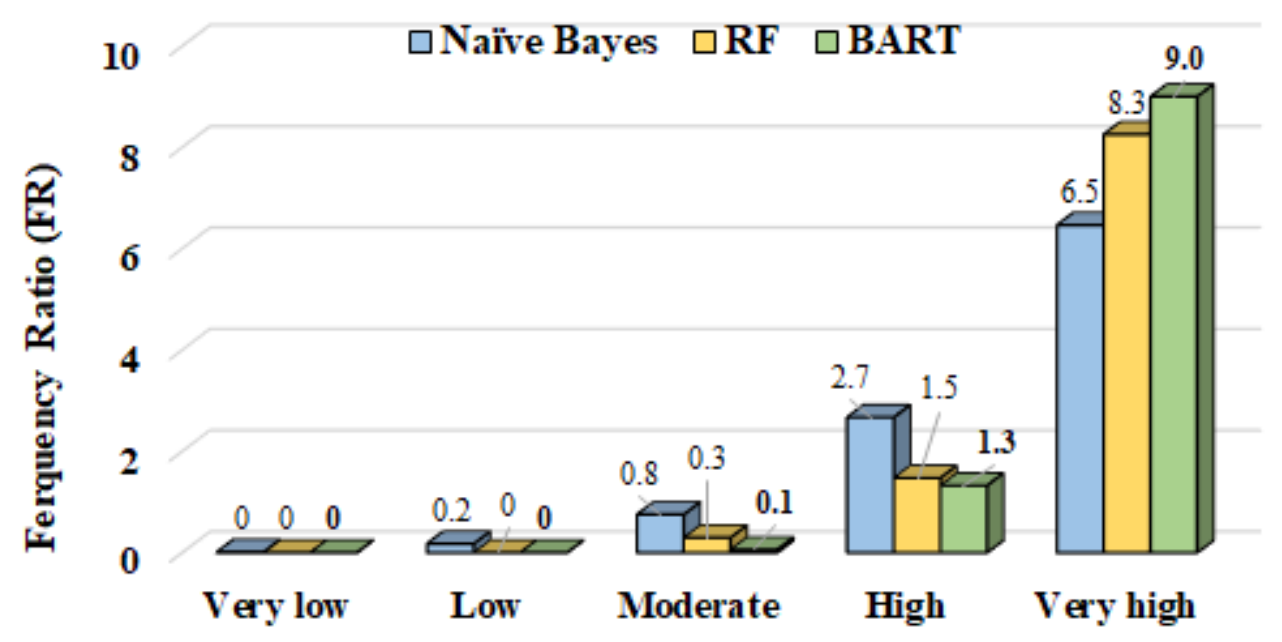

Flood susceptibility classes

Figure 12

Analysis of the frequency of floods on the flood susceptibility maps by FR method

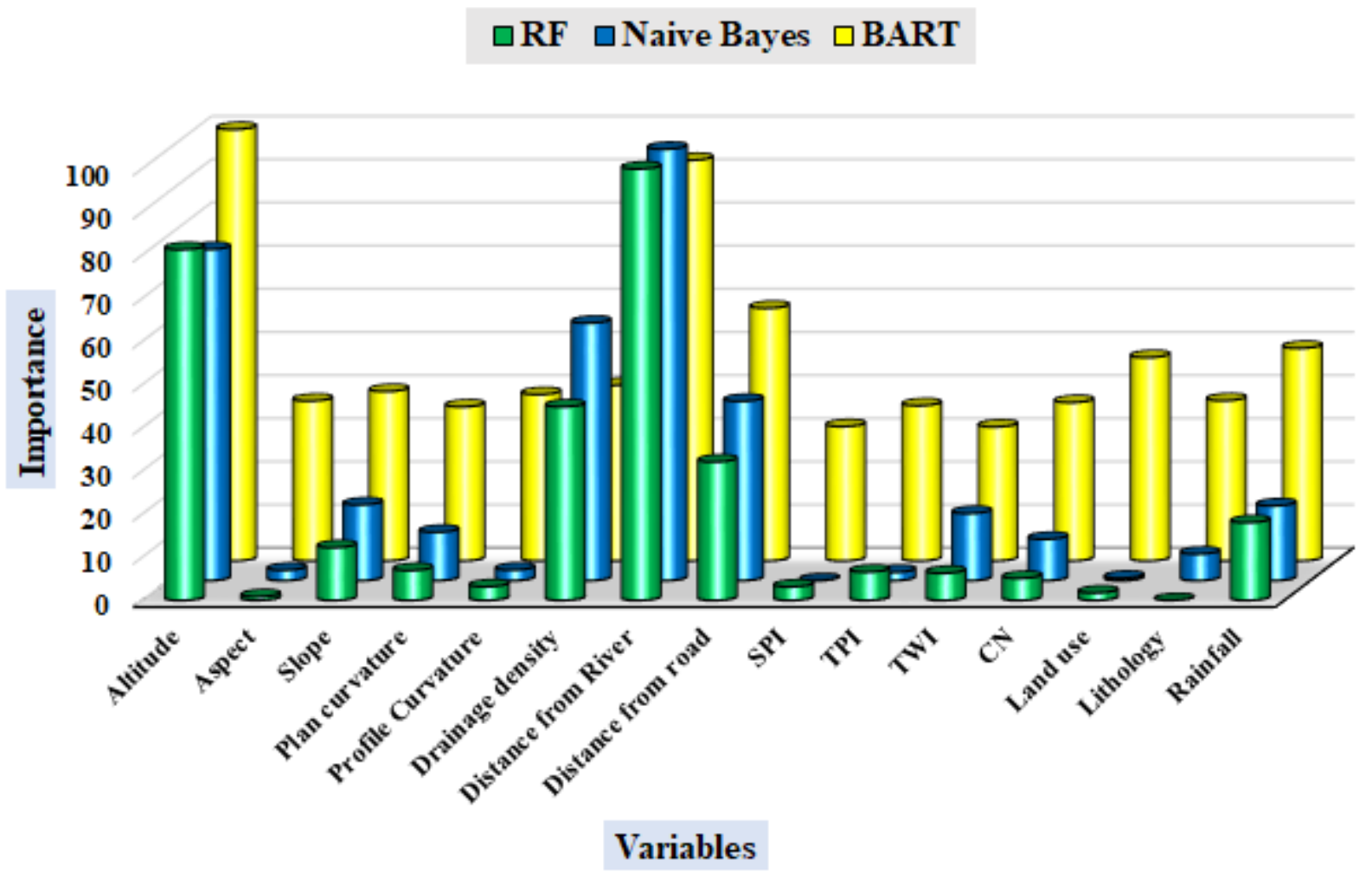

Figure 13

Results of relative importance of independent variables in flood sensitivity modeling in Naïve Bayes, RF and BART models 
Partial Dependence Plot

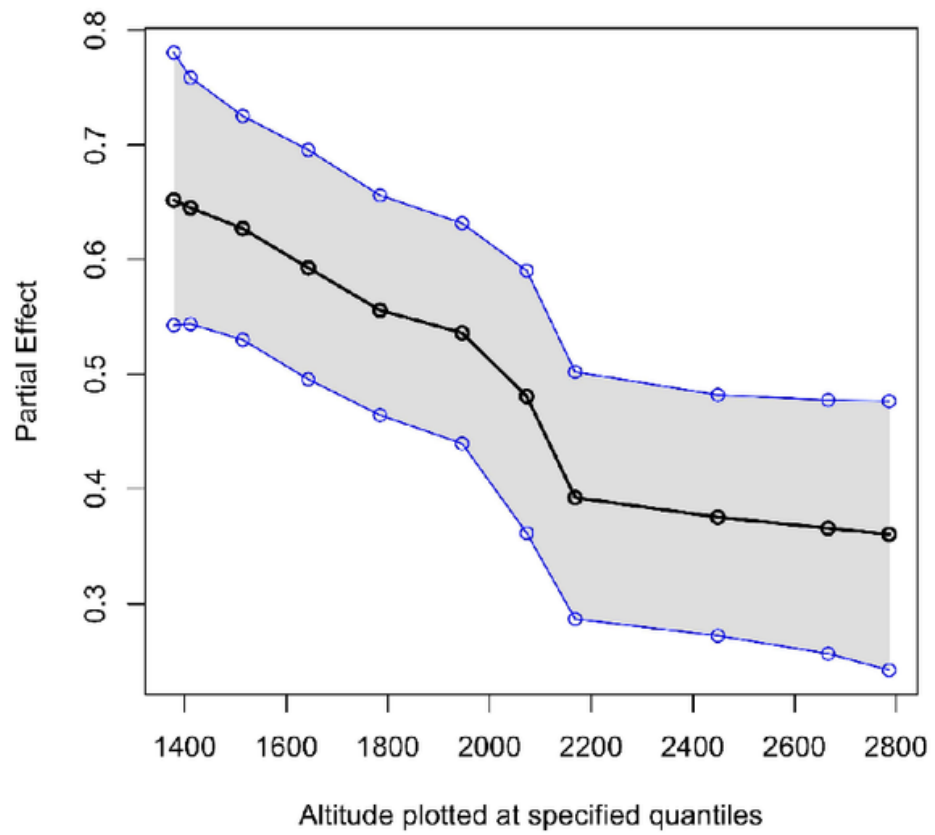

Partial Dependence Plot

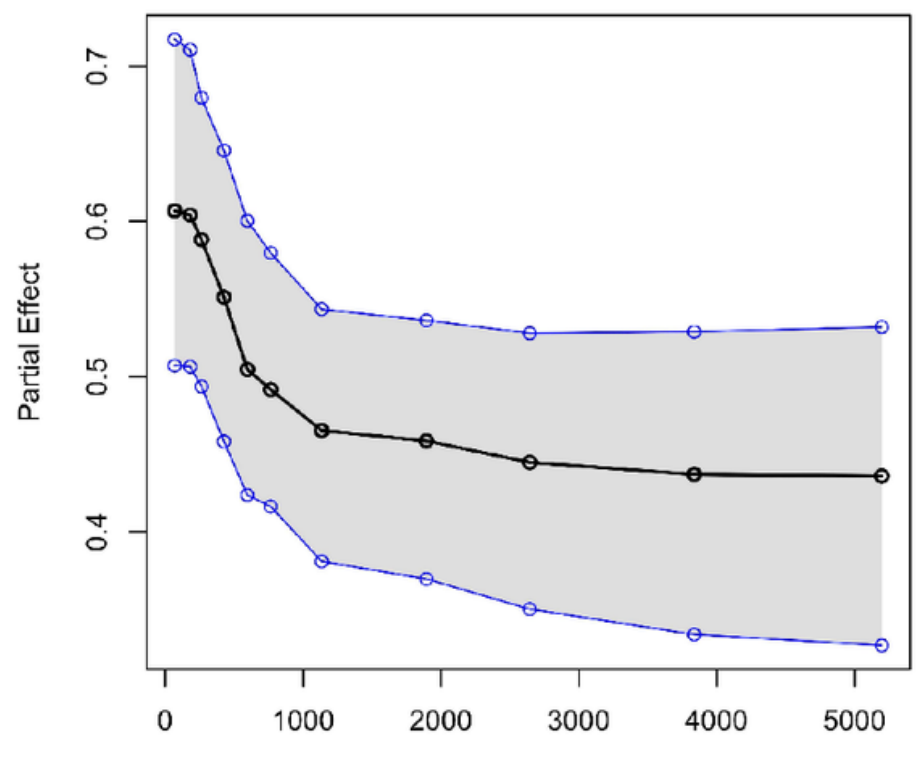

Distance.from.road plotted at specified quantiles
Partial Dependence Plot

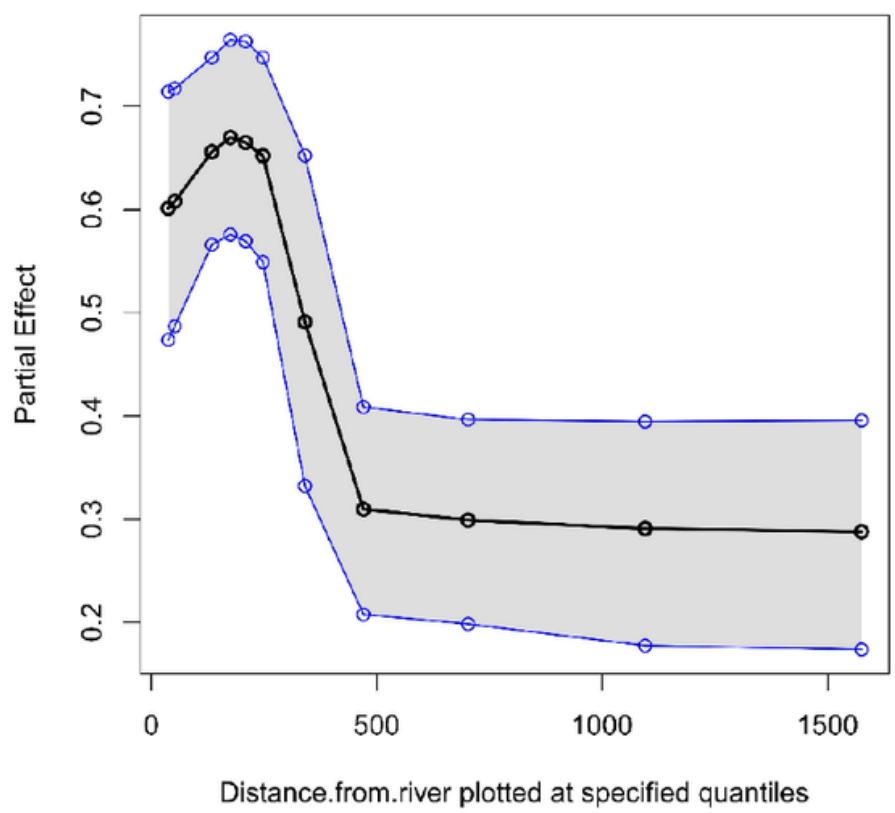

Partial Dependence Plot

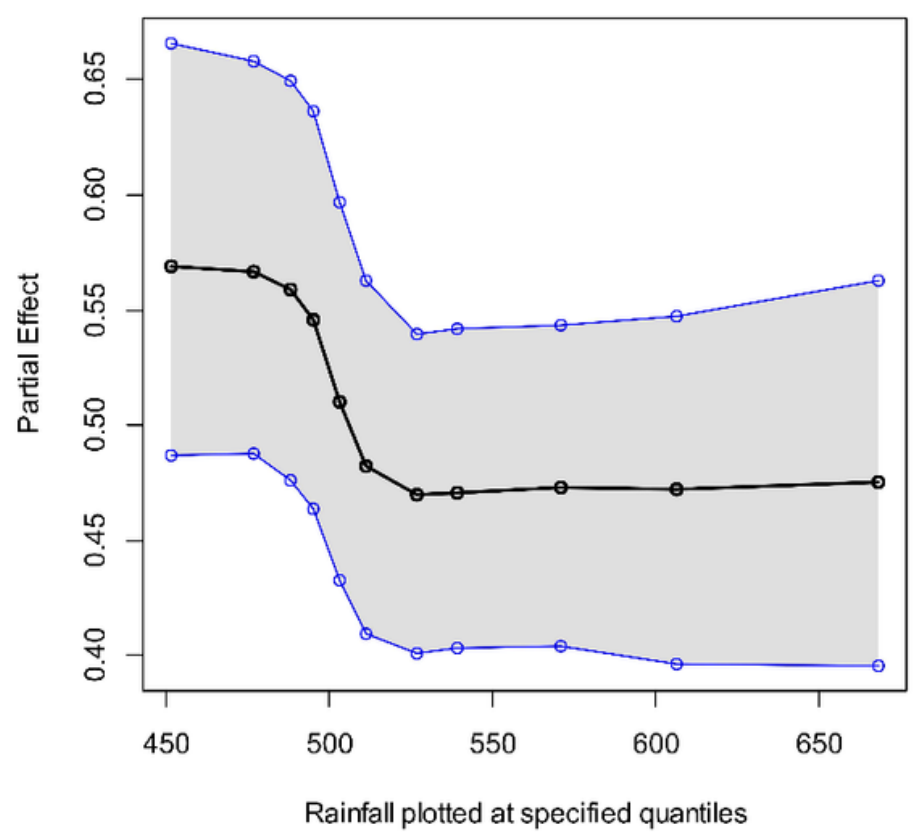

\section{Figure 14}

Partial effect plot for four importance variable (altitude, distance from river, distance from road and rainfall) 